\title{
LA EPIDEMIA DE 1488 EN CÓRDOBA ${ }^{1}$
}

\author{
THE 1488 EPIDEMIC IN CORDOBA
}

\section{MARgARITA CABRERA SÁNCHEZ Universidad de Córdoba ${ }^{2}$}

\begin{abstract}
Resumen: Este trabajo tiene como objetivo analizar la epidemia que afectó a la ciudad de Córdoba durante el año 1488. La utilización de la documentación notarial conservada en el Archivo Histórico Provincial de la ciudad nos ha permitido conocer la naturaleza y las posibles vías de transmisión de la enfermedad, el desarrollo de ese fenómeno epidémico y las medidas que adoptaron los habitantes de Córdoba para librarse de la epidemia.
\end{abstract}

Palabras clave: Enfermedad; Peste; Epidemia.

\begin{abstract}
This paper tries to analyze the epidemic that Cordoba suffered during 1488. The use of notarial documentation conserved in the city's Archivo Historico Provincial has allowed us to know the nature and the possible ways for disease's contagious, the development of this epidemic phenomenon and the measures for avoiding the epidemic that Cordoba's people adopted.
\end{abstract}

Keywords: Disease; Plague; Epidemic.

\section{SUMARIO}

I. Etiología y transmisión de la enfermedad.- II. El ritmo de la epidemia.- III. La huida de la peste.

[...] Este año de 1481 no fue propicio a natura humana en esta Andalucía, mas muy contrario e de gran pestilencia e muy general, que en todas las ciudades, villas y lugares de esta Andalucía murieron en demasiada manera, que en Sevilla murieron más de quince mil personas e otras tantas en Córdoba e en Xerez, e en Ezija más de cada ocho o nueve mil personas y ansí en todas las otras villas e lugares. E después en el agosto alzóse la pestilencia y con todo eso por más de ocho años duró, que poco o mucho acudía, ora en una parte, ora en otra de esta Andalucía. Y el año de 1488 murieron en Córdoba otra vez, generalmente decían, que aún más cantidad del año de ochenta y uno, ya dicho $[\ldots]^{3}$.

${ }^{1}$ Este trabajo forma parte del proyecto de investigación HUM2005-07240-C02-01/HIST, subvencionado por el Ministerio de Educación y Ciencia.

${ }^{2}$ Profesora titular de Historia Medieval. Departamento de Ciencias de la Antigüedad y de la Edad Media.

${ }^{3}$ Andrés BERnÁLDEZ, Crónica de los Reyes Católicos, vol. 70, ed. Biblioteca de Autores españoles (BAE), Madrid, 1953, p. 601. 
De este modo se refería el cronista Andrés Bernáldez a la catástrofe demográfica que, al parecer, padeció Andalucía durante la penúltima década del siglo XV. Poco después, en otro capítulo de su crónica, referido al año 1488, el citado autor añadía que ovo pestilencia en algunas partes, especialmente en Sevilla e en Toledo» ${ }^{4}$. El relato del cura de los Palacios, además de informarnos de la magnitud que pudo alcanzar ese fenómeno epidémico que se desencadenó en 1488, nos sitúa en el punto de partida para conocer la incidencia que este último pudo tener en lugares concretos de la región andaluza. Para ello, resulta de gran utilidad la consulta de la documentación notarial conservada en algunos archivos andaluces, gracias a la cual es posible analizar la naturaleza y la transmisión de la enfermedad contagiosa que provocó ese elevado número de víctimas, el ciclo evolutivo y el impacto demográfico de esa epidemia e incluso las medidas puestas en práctica por los contemporáneos para escapar del contagio.

A analizar todas estas cuestiones hemos dedicado el presente trabajo, con la intención de estudiar de forma detallada la epidemia de 1488 en la ciudad de Córdoba. Para ello, se ha realizado un vaciado completo de todos los legajos en los que existen actas notariales relativas a ese año, tratando de buscar noticias relativas a la enfermedad. En concreto, se han consultado media docena de legajos custodiados en el Archivo Histórico Provincial de Córdoba pertenecientes a las escribanías 14 y 18, ${ }^{5}$ que, junto con la escribanía 30 , son las únicas en las que se han conservado documentos notariales fechados en el siglo XV, aunque esta última escribanía no la hemos utilizado por no contener documentación relativa a $1488 .{ }^{6}$ En cualquier caso, la lectura de todos esos legajos permite recabar, en primer lugar, algunos testimonios en los que se alude de manera directa a la presencia de esa enfermedad de carácter epidémico entre los habitantes de la ciudad, consignando incluso datos relativos a la sintomatología con la que cursaba esta última. En segundo lugar, a la información facilitada por esos documentos hay que añadir los datos que proporciona la documentación testamentaria, que, aunque de forma menos directa, como veremos en su momento, también permite conocer los efectos que la citada epidemia pudo tener en Córdoba.

\section{ETIOLOGÍA Y TRANSMISIÓN DE LA ENFERMEDAD}

La primera cuestión que nos debemos plantear es la de conocer qué tipo de enfermedad infecciosa pudo provocar la gran mortandad del año 1488. Como es sabido, los contemporáneos solían utilizar el término «pestilençia» para aludir a numerosas dolencias de carácter contagioso a las que, en buena

\footnotetext{
${ }^{4}$ Ibidem, p. 634.

${ }^{5}$ Son los legajos 20, 21 y 22 de la escribanía 14 y los legajos 1, 2 y 6 de la escribanía 18.

${ }^{6}$ En Córdoba sólo se conserva una parte de las actas notariales que pudieron existir y sólo desde mediados del siglo XV.
} 
parte de los casos, no es fácil identificar con precisión. ${ }^{7}$ En el caso que nos ocupa, algunos indicios permiten suponer que la enfermedad epidémica que se extendió por Andalucía durante ese año pudo ser peste bubónica. ${ }^{8} \mathrm{Al}$ menos, es lo que se puede deducir de la lectura de algunos registros notariales cordobeses que se refieren a ciertas manifestaciones físicas -las «landres» y las «nasçidas», también denominadas bubas- que, aunque es cierto que podían estar presentes también en otras enfermedades infecciosas, eran especialmente características de la dolencia indicada. ${ }^{9}$ A esa sintomatología hace alusión un documento fechado el 22 de septiembre de 1487 que es, además, el primer testimonio que poseemos sobre la presencia de esa epidemia en la ciudad de Córdoba. Se trata de un acta notarial en la que dos cirujanos cordobeses, Juan Díaz de Torreblanca y maestro Alfonso, pronosticaban la muerte de un niño, hijo de un carcelero de la ciudad, que padecía «una grand calentura contina», «carbonche pestilençial» y «una landre», síntomas que sugieren la idea de que el pequeño tenía peste. ${ }^{10}$ Pero no volvemos a tener más indicios de la existencia de la enfermedad entre la población cordobesa hasta cinco meses más tarde. En febrero de 1488, tenemos constancia documental de haber fallecido «de landres» un moro de veinte años, llamado Çaçem, natural de la localidad malagueña de Osunilla ${ }^{11}$.

Sin embargo, habría que esperar varios meses, concretamente hasta el verano de ese año, para que empezasen a proliferar los documentos referidos a enfermos que, según apuntan todos los indicios, padecían peste. Durante el mes de junio, dos actas notariales registraban el fallecimiento, a causa «de pestylençia», de Hamete, un niño de seis años ${ }^{12}$ y de otro de tres llamado $\mathrm{Ali}^{13}$. El 7 de julio está documentado el fallecimiento, también a

${ }^{7}$ Así se pone de manifiesto en numerosos trabajos sobre el tema. Ver, por ejemplo, Antonio CARRERAS PANCHÓN, La peste y los médicos en la España del Renacimiento, Salamanca, 1976, p. 60 y Juan Ignacio CARMONA GARCÍA, La peste en Sevilla, Sevilla, 2004, p. 48. Sobre la peste durante el Medievo ver, entre otros, los siguientes trabajos: Marcelino AMASUNO SARRAGA, La peste en la Corona de Castilla durante la segunda mitad del siglo XV. Salamanca, 1996; Manuel CAMPS I CLEMENTE; Manuel CAMPS I SURROCA, La pesta del segle XV a Catalunya, Lérida, 1998; Peio Joseba MonTEANO, La ira de Dios. Los navarros en la era de la peste (1348-1723), Pamplona, 2002.

${ }^{8}$ Sobre las epidemias de peste en Andalucía a finales del Medievo ver: Margarita CABRERA SÁnCHEZ, La Medicina en Córdoba durante el siglo XV, Córdoba, 2002, pp. 42 y ss.

${ }^{9} \mathrm{Ver}$ sobre esta cuestión, el reciente trabajo de Ole J. BENEDICTOW, The black death 1356-1353. The complete history, Woodbridge, 2004, p. 25, así como la obra clásica de Jean Noël BIRABEN, Les hommes et la peste en France et dans les pays européens et méditerranéens, tomo 1, París, 1975 , p. 10.

${ }^{10}$ Archivo Histórico Provincial de Córdoba (AHPC), Protocolos Notariales (PN), 14-20(22), cuad. 5 f .40 v. 1487.09.22. Los legajos de protocolos notariales del Archivo Histórico Provincial de Córdoba han cambiado de signatura en varias ocasiones. Nosotros vamos a indicar el número del legajo según la primittiva signatura y, a continuación, entre paréntesis, consignamos también el número del legajo según la signatura nueva. No obstante, nos consta que esos legajos han sido sometidos a un nuevo cambio de signatura en época muy reciente.

${ }^{11} \mathrm{El}$ documento está fechado el 29 de agosto de 1488 , aunque en él se afirma que la muerte se había producido en el mes de febrero (AHPC, PN, 14-20(22), cuad. 4, f.16 r. 1488.08.29).

${ }^{12}$ AHPC, PN, 14-21(23), cuad. 7, f.15 r. 1488.06.06.

${ }^{13}$ AHPC, PN, 14-21(23), cuad. 7, f.35 r. 1488.06.13. 
consecuencia de la peste, de otros dos niños de corta edad: Alí $^{14}$ y Taçam ${ }^{15}$. En el mes de agosto, Beatriz de Hoces, mujer de Juan Tafur, regidor de Córdoba, otorgaba un documento en el que declaraba que el día 22 de julio había muerto, «de una landres», una mora de Málaga de unos 30 años llamada Lomulica ${ }^{16}$. Un mes antes, el 27 de junio, un registro notarial consignaba la muerte, a consecuencia de «una naçida», de Francisco, un esclavo negro de 11 años que era propiedad de un vecino de Córdoba llamado Alfonso Fernández ${ }^{17}$. Al día siguiente, otro testimonio se refería a las «dos nascidas» que presentaba otro vecino de la ciudad llamado Pedro de Valdelomar ${ }^{18}$.

Como se puede comprobar, entre todos esos enfermos abundan especialmente algunos musulmanes cautivos procedentes de Málaga, que, junto a otros muchos moros malagueños, llegaron a Córdoba y a otras localidades de Andalucía tras la toma de aquella ciudad, en el verano de 1487. A partir de este momento, fueron repartidos entre algunas familias andaluzas, que los tuvieron bajo su custodia aunque sólo de forma temporal, dado que esa población cautiva pertenecía a la Corona. Por ello, esos registros notariales en los que se consignaba el fallecimiento de los moros malagueños a consecuencia de la enfermedad, resultaban necesarios para que los cordobeses que los habían acogido pudieran demostrar las causas de la muerte de esos musulmanes ${ }^{19}$. La existencia de esos documentos y las noticias que aportan otros testimonios consultados nos permiten plantear la hipótesis de que, tal vez, fueron los cautivos de Málaga los que transmitieron la peste a los vecinos de Córdoba. Por una parte, cabe apuntar esa posibilidad si tenemos en cuenta el testimonio del erudito cordobés del siglo XIX L. de Maraver, quien, en su Historia de Córdoba, al narrar los sucesos acontecidos en la ciudad en 1487, señalaba:

[...] Por el mes de noviembre se padecía epidemia en Córdoba. Así consta de un auto capitular del cavildo de la catedral en el que se da licencia a los capellanes de la Sangre para que se pudiesen ausentar de esta ciudad durante el contagio, que provino de la gente de guerra que con los reyes vino de la campaña de este año, trayendo especialmente dicho contagio los moros cautivos $[\ldots]^{20}$.

Por su parte, el cronista $\mathrm{H}$. del Pulgar, al referirse al cerco de Málaga, señalaba textualmente:

\footnotetext{
${ }^{14}$ AHPC, PN, 14-21(23), cuad. 4, f.6 r. 1488.07.07.

${ }^{15}$ AHPC, PN, 14-21(23), cuad. 4, f.9 v. 1488.07.07.

${ }^{16} \mathrm{El}$ registro notarial corresponde al mes de agosto aunque en él se indicaba que la muerte se había producido el 22 de julio (AHPC, PN, 14-20(22), cuad. 4 , f.4 r. 1488.08.s.d).

${ }^{17}$ AHPC, PN, 14-21(23), cuad. 5, f.10 v. 1488.06.27.

${ }^{18}$ AHPC, PN, 14-21(23), cuad. 5, f.27 r. 1488.06.28.

${ }^{19}$ Sobre los moros malagueños que fueron repartidos entre los habitantes de Córdoba ver: Margarita CABRERA SÁNCHEZ, El destino de los cautivos llegados a Córdoba tras la toma de Málaga, «Homenaje al profesor Julio Valdeón» (en prensa).

${ }^{20}$ Luis de MARAVER Y AlFARO, Historia de Córdoba, Biblioteca Municipal de Córdoba, rollo B-30, año 1487 .
} 
En algunos lugares de los que son en comarca de la cibdad de Málaga había en aquellos días pestilencia e las gentes de la hueste por esta causa estaban en temor recelando no la oviese en el real $[\ldots]^{21}$.

Pero ése es el único dato que hemos conseguido recopilar sobre la posible presencia de la enfermedad durante el asedio. ${ }^{22}$ En cambio, sí estamos bien informados de las duras condiciones de vida que tuvieron que soportar los musulmanes de Málaga tras el largo cerco. Los testimonios cronísticos de la época se refieren al estado de desnutrición en el que quedaron los habitantes de esa ciudad, quienes, según relataba A. Bernáldez, «se morían de hambre ${ }^{23}$. La misma situación describe D. de Valera, quien afirmaba:

Martes bísperas de Nuestra Señora de agosto, en la mañana, salió un moro mancebo e dixo al rey que él, no queriendo morir de hanbre, se salía; e que se maravillava mucho de los moros poder sufrir tan grand hanbre e lazería quanto avían sostenido e sostenían e que era imposible poderlo más sostener $[\ldots]^{24}$.

Esas carencias alimenticias tuvieron mucho que ver, sin duda, con el estado de debilidad en el que llegaron a Córdoba esos cautivos durante el otoño de 1487. La mayor parte de ellos padecían dolencias de tipo gastrointestinal, a juzgar por los síntomas que aparecen descritos en la documentación conservada. Así, por ejemplo, del 6 de octubre de 1487 es un documento otorgado por un labrador llamado Alfonso de Castro, donde se deja constancia de la muerte de un moro malagueño llamado Mahomad del que se especificaba literalmente que «venya mucho mal de cámaras» ${ }^{25}$. Unos días después, las actas notariales consignan la muerte de dos moros de avanzada edad, Avdalla y Haxa, aquejados también de esa misma afección de tipo digestivo ${ }^{26}$. En otras ocasiones, los testimonios son más parcos en noticias y, aunque no aludían al tipo de dolencia que padecían algunos musulmanes malagueños, señalaban que estos últimos ya estaban enfermos cuando llegaron a Córdoba. Es el caso, entre otros, de una mora llamada Marrata, muerta a mediados de octubre de ese año, y de la que se especificaba que «venya doliente $»^{27}$.

Aunque, en realidad, ninguno de estos documentos alude a la peste como causa de la muerte de esos cautivos, es fácil imaginar que el estado de consunción en el que llegaron muchos de ellos puede explicar por sí mismo

\footnotetext{
p. 459 .

${ }^{21}$ Hernando del Pulgar, Crónica de los Reyes Católicos, vol. 70, ed. BAE, Madrid, 1953,

${ }^{22} \mathrm{El}$ cronista A. Bernáldez no aporta ningún dato al respecto (Andrés BERNÁLDEZ, Crónica de los Reyes Católicos, vol. 70, ed. cit., pp. 626 y ss).

${ }^{23}$ Ibidem, p. 631.

${ }^{24}$ Diego de Valera, Crónica de los Reyes Católicos, ed. Carriazo, Madrid, 1927, p. 265.

${ }^{25}$ AHPC, PN, 14-20(22), cuad. 3, f.10 v. 1487.10.06.

${ }^{26}$ AHPC, PN, 14-20(22), cuad. 3, f.22 r. 1487.10.14; AHPC, PN, 14-20(22), cuad. 3, f.23 r. 1487.10 .17

${ }^{27}$ AHPC, PN, 14-20(22), cuad. 3, f.22 r. 1487.10.14.
} 
el que fueran estos últimos quienes más sufrieran el embate de la peste que se desató en Córdoba en 1488. Pero, además, considerando el testimonio ya citado de L. de Maraver ${ }^{28}$, tampoco podemos dejar de considerar la posibilidad de que una parte de esos moros de Málaga que llegaron a Córdoba a partir del otoño de 1487 viniesen ya enfermos de peste, aunque la documentación relativa a los meses de octubre y noviembre no se refiera específicamente a esa dolencia y haya que esperar al verano del año siguiente para encontrar documentos en los que se aluda, de forma explícita, a los musulmanes malagueños aquejados de esa enfermedad. En cualquier caso, no debemos descartar la existencia de esa supuesta vía de transmisión de la epidemia, a los habitantes de Córdoba, a través de los moros malagueños que pudieron llegar a esta última ciudad siendo ya portadores de la peste.

Otros testimonios nos llevan a considerar la posibilidad de una segunda vía de contagio directo de la epidemia de 1488, en este caso desde Sevilla a Córdoba. Así, por ejemplo, varias anotaciones conservadas en los registros notariales sevillanos y fechadas en 1486 apuntan hacia esa dirección. El 20 de mayo un escribano afirmaba textualmente:

En este día salí de Sevilla yo e mi casa, fuyendo de la pestilençia, a Palomares ${ }^{29}$.

Y en otra nota consignada por este último a comienzos de ese mismo mes, se especificaba lo siguiente:

En este día dio una nasçida e su fija de Juan Martínez Viscayno fallesçió en miércoles III de mayo ${ }^{30}$.

Parece evidente, por tanto, que, durante la primavera de ese año, los sevillanos sufrían los efectos de una epidemia de peste, que, además, siguió estando latente en esa ciudad durante los años siguientes. En 1487, durante la segunda mitad de ese año, según ha podido constatar J.I. Carmona, se detectó en Sevilla la llegada de numerosas personas procedentes de Ecija y Marchena, lugares en los que había peste. En 1488 la epidemia se había extendido ya por la ciudad de Sevilla y, al parecer, se mantuvo hasta el año $1489^{31}$. Por su parte, A. Collantes también hace alusión a la peste que padeció la ciudad en 1488, pues, según señala el citado autor, en un cabildo celebrado el 16 de abril de ese año, se dotó con 10.000 mrs. la procesión a San Juan «por la peste que hauía este año» ${ }^{32}$. También alude a la epidemia J. Matute y Gaviria, quien, refiriéndose al año 1488, señalaba que la ciudad de Sevilla padeció

\footnotetext{
${ }^{28}$ Luis de Maraver y Alfaro, Historia de Córdoba, rollo B-30, año 1487.

${ }^{29}$ José BONO; Carmen UNGUETI-BONO, Los protocolos sevillanos de la época del descubrimiento, Sevilla, 1986, p. 182.

${ }^{30}$ Ibidem.

${ }^{31}$ Juan Ignacio CARMONA GARCÍA, Ob. cit., p. 76.

32 Antonio COllantes DE TERÁn, Sevilla en la Baja Edad Media. La ciudad y sus hombres, Sevilla, 1977, p. 164, nota n$^{0} 56$.
} 
«una grande pestilencia» ${ }^{33}$. En todo caso, la epidemia que se extendió por esta última ciudad en 1486, a la que hicimos alusión anteriormente, y la posible presencia de la peste durante el cerco de Málaga, al año siguiente, nos lleva a plantear la posibilidad de que la enfermedad se transmitiera de forma directa desde Sevilla a Málaga — ciudad a partir de la cual el contagio pudo llegar a Córdoba en otoño de 1487 a través de los moros malagueños enfermos- y también desde Sevilla a Córdoba, dadas las estrechas relaciones que existían entre estas dos ciudades.

\section{EL RITMO DE LA EPIDEMIA}

Pero, ¿cuál pudo ser la evolución de la epidemia de 1488 en la ciudad de Córdoba? La falta de fuentes idóneas nos impide conocer con precisión el ritmo y la duración de la enfermedad. En algunos estudios referidos a determinados lugares en los que se han conservado fuentes adecuadas para analizar el problema, se pone de manifiesto que las epidemias de peste tenían una vigencia muy variable. Así, por ejemplo, J. N. Biraben, que estudió la incidencia del ciclo epidémico de 1720-1722 en las distintas localidades de Provenza, pudo comprobar que, si bien en muchas de estas últimas la epidemia tuvo una duración corta (hasta 49 días), también fueron muy numerosas las localidades en las que la peste se prolongó entre 50 y 149 días. Y tampoco faltan ejemplos de algunos núcleos de población de esa región francesa en los que la enfermedad persistió durante más de un año ${ }^{34}$. En el caso de Córdoba, los indicios documentales que poseemos permiten suponer que la peste de 1488 tuvo un ciclo largo, considerando que, como ya tuvimos ocasión de comprobar con anterioridad, aunque la enfermedad empezó a manifestarse de forma tímida a partir del otoño de 1487, alcanzó su momento más álgido durante el verano del año siguiente.

Ello se comprueba fácilmente, en primer lugar, si tenemos en cuenta que, salvo dos testimonios aislados ya citados que hacen alusión a la presencia de la peste en septiembre de 1487 y en febrero de 1488, los documentos en los que se alude de forma explícita a la enfermedad proliferan a lo largo de los meses estivales. Se ha hecho referencia ya a los registros fechados en junio y julio de 1488, en los que se dejaba constancia de la muerte, como consecuencia de esa enfermedad, de varios vecinos de Córdoba, entre los que figuraban algunos musulmanes procedentes de Málaga ${ }^{35}$. Pero, además, unos meses

\footnotetext{
${ }^{33}$ «Padeció Sevilla este año una grande pestilencia, de que nos habla nuestro analista Zúñiga. De ella nos ha quedado memoria en la dotación que el 16 de junio del citado año hizo el cabildo eclesiástico para la estación que con dicho motivo se hacía en la Iglesia parroquial de San Juan de Palma» (Justino MATUTE Y GAVIRIA, Noticias relativas a la historia de Sevilla, Sevilla, 1982, p. 48).

${ }^{34}$ Jean Noël BIRABEN, Ob. cit., tomo 1, p. 292. Ver también la tabla de esta página.

${ }^{35} \mathrm{AHPC}, \mathrm{PN}, 14-21(23)$, cuad. 7, f.15 r. 1488.06.06; AHPC, PN, 14-21(23), cuad. 7, f.35 r. 1488.06.13; AHPC, PN, 14-21(23), cuad. 5, f.10 v. 1488.06.27; AHPC, PN, 14-21(23), cuad. cuad. 4 , f.9 v. 1488.07.07. A todos ellos hay que añadir otro documento fechado en agosto en
} 
después, en noviembre y diciembre, varias actas notariales aludían, de forma retrospectiva, a la huida de algunos vecinos de la ciudad unos meses antes, es decir durante el verano, tratando de escapar de la epidemia ${ }^{36}$. En todos esos casos, las anotaciones de los escribanos concernientes a las manifestaciones físicas de la enfermedad y al abandono de la ciudad para evitar el contagio no dejan lugar a dudas sobre el hecho de que la peste afectó con especial intensidad a los habitantes de Córdoba durante la época estival y, en concreto, durante los meses de junio y julio. Posiblemente, el contagio comenzó a cesar a partir de estas fechas, si tenemos en cuenta que desde ese momento, y hasta finales de 1488, en la documentación conservada no hay alusiones directas a la peste.

Por otra parte, contamos con la existencia de otros testimonios documentales - los testamentos-, que, aunque aparentemente son menos explícitos que los anteriores, permiten conocer también el desarrollo de la epidemia de 1488 y la especial intensidad que esta última alcanzó durante el verano. Y es que, en ausencia de fuentes demográficas adecuadas, el análisis cuantitativo de la documentación testamentaria puede servir para medir, aunque sólo sea de forma aproximada, el impacto que esa epidemia pudo tener sobre la población cordobesa. Para ello, resulta imprescindible localizar todos los testamentos que fueron otorgados en la ciudad durante ese año y, posteriormente, comparar el volumen de estos últimos con el número de actas testamentarias otorgadas durante otros años de aparente normalidad demográfica. En un principio, decidimos escoger dos años que no estuvieran demasiado alejados, desde el punto de vista cronológico, al año 1488 y, por ello, seleccionamos los años 1478 y 1498. Sin embargo, el número de testamentos que se contiene en los dos legajos en los que existe documentación relativa a $1498^{37}$ es tan exiguo - sólo figuran cinco-, que no nos pareció adecuado utilizarlos como elemento comparativo. Probablemente, sea la pérdida anormal de documentación relativa a ese año la que explique ese escaso número de actas testamentarias. En cualquier caso, ello nos ha obligado a buscar otro año, con el fin de realizar el estudio comparativo. Nos hemos decantado por 1482, sobre el cual existe una abundante documentación notarial distribuida, además, a lo largo de numerosos legajos ${ }^{38}$.

Después de contabilizar los testamentos que se otorgaron en 1488, en 1482 y en 1478 , los resultados obtenidos hablan por sí solos. El elevado número de 345 testamentos que se redactaron en Córdoba en 1488 contrasta de manera muy significativa con el volumen de actas testamentarias corresel que se aludía a la muerte durante el mes anterior, de una mora de Málaga (AHPC, PN,
$14-20(22)$, cuad. 4 , f.4 r. 1488.08 .s.d).

${ }^{36}$ AHPC, PN, 14-21(23), cuad. 18, f.3 v. 1488.11.11; AHPC, PN, 14-21(23), cuad. 18, f.29 v. 1488.12 .02 .

${ }^{37}$ Se trata del legajo 5 del oficio 14 y del legajo 6 del oficio 18 .

${ }^{38}$ En concreto, hay documentos de ese año en los legajos 5, 7, 8 y 13 del oficio 14, y en los legajos 1 y 6 del oficio 18 . 
pondientes a los años 1482 y 1478 , que ascienden a 69 y a 26 respectivamente. Todos esos datos arrojan una media de 28.75 testamentos al mes en el caso del año 1488, frente a 5.75 y 2.16 en 1482 y 1478 respectivamente. Es evidente que, detrás de esa desmesurada cifra de testamentos registrados durante el año 1488, se esconde el miedo a contraer una epidemia que estaba causando estragos entre los vecinos de la ciudad y, en definitiva, la urgencia por ordenar las últimas voluntades en un momento en el que la muerte se sentía próxima. En ese sentido, hace ya algunas décadas, J.N. Biraben, al referirse a la famosa epidemia de 1348, señalaba, con una frase muy gráfica, que «la mortalidad conducía a los hombres, no sólo ante el confesor, sino también ante el notario» ${ }^{39}$. En cualquier caso, ese volumen desmesurado de testamentos durante períodos epidémicos ha podido también ser constatado en algunos estudios sobre el tema. Así, por ejemplo, en Londres, el número aproximado de 40 testamentos anuales registrados antes de la famosa epidemia de Peste Negra, ascendió a 360 en el año 1349. Y lo mismo sucedió en la localidad francesa de Besançon, en la que el volumen de testamentos otorgados en $1347-14-$ se elevó a 161 en $1349^{40}$. Dos siglos después, en Barcelona, a lo largo de 1589, año en el que tuvo lugar una epidemia de peste, el número de testamentos registrados ascendió a 220, frente a 148, 134, 106 y 119 otorgados durante los años $1587,1588,1590$ y 1591 respectivamente $^{41}$. Y lo mismo sucedió en Huelva durante el difícil año de 1709, en el cual el número de testamentos que se otorgaron multiplicaba por tres o por cuatro la cifra de actas testamentarias de los años anterior y posterior ${ }^{42}$.

Por otra parte, nos ha parecido interesante analizar el número de testamentos que se redactaron durante cada uno de los meses del año 1488, con el fin de conocer con precisión los períodos estacionales en los que la enfermedad golpeó con mayor intensidad a los habitantes de Córdoba. Sin embargo, hay que tener en cuenta que, en algunos casos, el deterioro de las actas testamentarias nos impide conocer la fecha exacta en la que fueron redactadas algunas de estas últimas. Es lo que sucede con seis testamentos, acerca de los cuales el único dato cronológico que poseemos es que se otorgaron en el año $1488^{43}$. Por tanto, la distribución de testamentos a lo largo de los diferentes meses no la vamos a realizar sobre el total de 345 testamentos fechados durante ese año, sino únicamente sobre 339, que son aquellos de

\footnotetext{
${ }^{39}$ Jean Noël BIRABEN, Ob. cit., tomo 1, p. 174.

${ }^{40}$ Ibidem, tomo 1, p. 171.

${ }^{41}$ José Luis Betrán, La peste en la Barcelona de los Austrias, Lérida, 1996, p. 450.

${ }^{42}$ David GONZÁLEZ CRUZ, Religiosidad y ritual de la muerte en la Huelva del siglo de la Ilustración, Huelva, 1993, p. 514. Ese mismo fenómeno también pudo ser constatado por A. Pastore, quien tuvo ocasión de comprobar que el volumen de testamentos otorgados en Bolonia en el año 1630, en el que tuvo lugar una epidemia de peste, era mucho más elevado que el registrado durante los anos anteriores y posteriores (Alessandro PASTORE, Testamenti in tempo di peste: la pratica notarile a Bologna net 1630, «Società e Storia», 16 (Milan, 1982), p. 264. Ver las tablas de esa página).

${ }^{43}$ AHPC, PN, 14-21(23), cuad. 2, f.55 r. 1488.s.m.s.d.; AHPC, PN, 14-21(23), cuad. 6, f.13 r. 1488.s.m.s.d.; AHPC, PN, 14-21(23), cuad. 2, f.1 r. 1488.s.m.s.d.; AHPC, PN, 14-21(23) cuad.6, f.2 r. 1488. s.m.s.d.; AHPC', PN, 14-21
} 
los que conocemos de manera precisa el mes en el que fueron otorgados. Los resultados obtenidos son los siguientes: en enero se otorgaron 5 actas testamentarias; en febrero, 18; en marzo, 19; en abril, 24; en mayo, 7; en junio, 129; en julio, 73; en agosto, 25; en septiembre, 23; en octubre, 11; en noviembre, 5 (véase gráfico 1 , al final del artículo).

Como se puede apreciar, no hemos incluido ningún dato relativo a diciembre porque no se ha localizado ningún testamento fechado durante este mes. Por esa razón, no se ha tenido en cuenta este último mes del año a la hora de calcular la media de actas testamentarias redactadas cada mes. En cualquier caso, hemos podido comprobar que, a lo largo de los 11 meses restantes del año 1488, se registró una media de 30.81 testamentos al mes. Sin embargo, y dado que la dispersión entre los distintos meses es muy alta, nos ha parecido significativo calcular, por separado, la media de actas testamentarias redactadas durante los meses de junio y julio, en los que el número de testamentos asciende a 202, y a lo largo de los nueve meses restantes. En junio y julio la media obtenida es de 101 testamentos al mes. Por el contrario, en los otros nueve meses, esa media se sitúa en 15.22.

Parece lógico pensar, por tanto, que la epidemia dejaba sentir sus efectos de manera especial a lo largo del verano del año 1488 y, en concreto, durante los meses de junio y julio, si tenemos en cuenta que el número de testamentos registrados en esos dos meses representa el 59.58\% del total de actas testamentarias otorgadas a lo largo de todo el año ${ }^{44}$. En ese sentido, la epidemia de 1488 responde al ciclo estacional que solían presentar las epidemias de peste bubónica, que, como es sabido, tendían a manifestarse con mayor asiduidad durante el verano ${ }^{45} \mathrm{y}$, especialmente, cuando la temperatura oscilaba entre los 25 y los 30 grados, momento en el que el agente transmisor de la enfermedad se desarrolla con más facilidad ${ }^{46}$. En el caso de Córdoba, es fácil imaginar que la peste de 1488 se cebase con especial intensidad en el mes de junio si tenemos en cuenta tanto el desmesurado número de 129 testamentos registrados durante ese mes como las peculiaridades climáticas propias de esa época del año. Como es obvio, desconocemos la evolución que experimentó la meteorología en la ciudad a comienzos del verano de 1488, pero lo normal es pensar que esta última respondía al comportamiento que es habitual en Córdoba, en la cual, al menos en el último tercio del siglo XX, las temperaturas medias del mes de junio oscilaron entre los 15.5 y los 31.6 grados de mínima y de máxima respectivamente ${ }^{47}$. Probablemente, la actividad

\footnotetext{
${ }^{44}$ Algo parecido sucedió en Barcelona un siglo después, con motivo de la citada epidemia de 1589 , pues, según pudo comprobar en su día $\mathrm{J}$. L. Betrán, de los 220 testamentos redactados a lo largo de todo ese año, 170 (77.27\%), se otorgaron entre los meses de julio y diciembre, coincidiendo con el transcurso de la epidemia (Jose Luis BETRÁN, Ob. cit., p. 450 y cuadro de la p. 451).

${ }^{45}$ Jean Noël BIRABEN, $O b_{\text {. cit. }}$, tomo 1, p. 15. Sobre esta cuestión, ver también el capítulo 3 de esa obra y en concreto el interesante apartado de ese capítulo dedicado a la estrecha relación existente entre la climatología y las epidemias (Ibidem, tomo 1, pp. 134 y ss).

${ }^{46}$ Edouard Joltrain, La peste. Etiologie, formes cliniques, prophylaxie et traitement, París, 1921 , p. 98.

${ }^{47}$ Estos son los valores registrados en el observatorio del Aeropuerto de la ciudad.
} 
del agente transmisor de la peste comenzó a cesar a partir del mes de julio, si tenemos en consideración que el calor excesivo frenaba la reproducción de este último $^{48}$ y que la ciudad de Córdoba se caracteriza por padecer veranos con temperaturas muy elevadas ${ }^{49}$. De hecho, hemos contabilizado el número de testamentos que se redactaron en cada una de las cuatro quincenas de los meses de junio y julio y hemos podido comprobar que el mayor volumen de actas testamentarias - 74- se registró durante la primera quincena de junio. En la segunda quincena de ese mes se otorgaron 40 testamentos ${ }^{50}$ y un número similar - 48 - se redactaron durante los primeros 15 días de julio. A partir de este momento, el volumen de documentación testamentaria empieza a decrecer hasta el punto de que, en la segunda quincena de este último mes, se otorgaron sólo 15 testamentos ${ }^{51}$.

Pero, si el ingente volumen de testamentos correspondientes al año 1488 evidencia de forma clara la presencia de la epidemia, el análisis cualitativo de esa documentación testamentaria permite confirmar la intensidad del fenómeno epidémico. Aunque, como es sabido, los testamentos son documentos dotados de una estructura bastante rígida, hemos podido comprobar que esta última sufrió alteraciones significativas en el caso de las actas testamentarias otorgadas en el año $1488 \mathrm{y}$, especialmente, durante el verano de ese año. Los testamentos otorgados durante los meses estivales presentan cambios sustanciales en cuanto a su tamaño - tienden a ser mucho más breves- y a su redacción, hasta el punto de ser mucho más esquemáticos. Es lo que sucede, por ejemplo, durante los primeros días de junio y julio, en los que se registraron actas testamentarias más escuetas y más esquemáticas de lo habitual. Así, por ejemplo, hemos constatado ese hecho con los 18 testamentos que se otorgaron el 7 de junio. De ellos, el $61.11 \%$ ocupan menos de un folio y medio ${ }^{52}$. El $38.88 \%$ restante tienen una extensión igual o superior a folio y medio $\mathrm{y}$, entre todos ellos, no hay ningún testamento largo,

\footnotetext{
${ }^{48}$ Jean Noël BIRABEN, Ob. cit., tomo 1, pp. 13, 15 y 137.

${ }^{49}$ Las temperaturas medias de los meses de julio y agosto, durante el último tercio del siglo $\mathrm{XX}$, oscilaron entre los 18.1 y los 36.2 y los 18.5 y los 35.9 grados respectivamente.

${ }^{50} \mathrm{El}$ resto de testamentos fechados en junio de 1488 - 15- no presentan indicación del día.

${ }^{51}$ El resto de actas testamentarias fechadas en julio - 10- no presentan indicación del día.

${ }^{52}$ Antes de consignar la extensión de esos testamentos, es necesario aclarar que los protocolos notariales cordobeses del siglo XV no usan propiamente el formato de folio, sino el de cuartilla, independientemente de que, en el texto, usemos la primera de esas expresiones y no la segunda, que sería más exacta. Además, conviene también tener en cuenta que, cuando usamos el têrmino folio para consignar la extensión de esos testamentos, no nos referimos al folio completo con sus dos caras, sino a una de estas últimas. A continuaciọn, indicamos la identidad de los testadores --en algunos casos sólo conocemos el nombre de pila-- y la extensión de los testamentos. Los datos son los siguientes: Catalina Ruiz, un folio (AHPC, PN, 14-21(23), cuad. 7, f. $16 \mathrm{r}$. 1488.06.07); Pedro, un folio (AHPC, PN, 14-21(23), cuad. 7, f.18 r. 1488.06.07); Juan, algo más de medio folio (AHPC, PN, 14-21(23), cuad. 7, f.18 v. 1488.06.07); Catalina Fernández, un folio (AHPC, PN, 14-21(23), cuad. 7, f.19 v. 1488.06.07); Isabel García, un folio (AHPC, PN, 14-21(23), cuad. 7 f.20 r. 1488.06.07); Pedro Jiménez, algo menos de un folio (AHPC, PN, 14-21(23), cuad. 7, f. 20 v. 1488.06.07); Pedro, un folio (AHPC, PN, 14-21(23), cuad. 2, f.3 r. 1488.06.07); Beatriz, un folio (AHPC, PN, 14-21(23), cuad, 2 , f.5 r 1488.06.07); Pedro Martínez, un folio (A'HPC, PN, 14-21(23), cuad. 2, f.5 v. 1488.06.07); María Díaz, algo más de un folio (AHPC, PN, 14-21(23), cuad. 2, f.6 r. 1488.06.07); Antonia Ruiz, algo más de un folio (AHPC, PN, 14-21(23), cuad. 2, f.7 r. 1488.06.07).
} 
de más de dos folios ${ }^{53}$. También son muy lacónicas varias actas testamentarias redactadas el 8 de julio. Este día otorgó su última voluntad Gómez de Sandoval, hijo de Fernando Páez de Castillejo, regidor de Córdoba. En este caso, resulta especialmente llamativo comprobar que el tamaño del testamento de este individuo - ocupa sólo medio folio- no responde al esquema habitual que presentan los testamentos de los miembros de la nobleza, que, por lo general, son documentos cuya extensión suele ser especialmente notable, debido a la mayor disposición de bienes ${ }^{54}$. Igual que en el caso anterior, también son muy breves otros dos testamentos registrados ese mismo día. Sus otorgantes fueron María Ruiz e Isabel Fernández y cada uno de ellos ocupa sólo un folio ${ }^{55}$. En definitiva, todas esas actas testamentarias otorgadas el 7 de junio y el 8 de julio presentaban un tamaño considerablemente inferior al que era habitual y ese hecho se comprueba fácilmente comparando ese tamaño con el de los testamentos otorgados durante otros meses del año 1488 en los que, probablemente, el contagio ya había remitido. Así, por ejemplo, de los 11 testamentos registrados durante el mes de octubre, sólo cuatro, es decir el $36.66 \%$ del total, ocupaban menos de un folio y medio ${ }^{56}$. Los siete restantes, el $63.63 \%$ del total, eran testamentos de extensión igual o superior a folio y medio ${ }^{57}$. Y resultados muy similares obtenemos al observar la estructura de las actas testamentarias fechadas durante algunos años de normalidad demográfica. Así, por ejemplo, si entre los testamentos otorgados el 7 de junio de 1488 el $61.11 \%$ ocupaban menos de un folio y medio, durante el año 1482, el porcentaje de actas testamentarias con esa misma extensión se sitúa en el $33.33 \%$. El resto de los testamentos redactados en 1482, el $66.66 \%$, fueron más largos, de extensión igual o superior a un folio $\mathrm{y}$ medio ${ }^{58}$. Y en 1478 , sobre el total de 26 actas testamentarias registradas ese año, conocemos

\footnotetext{
${ }^{53}$ Antón Rodríguez, dos folios (AHPC, PN, 14-21(23), cuad. 7, f.14 r. 1488.06.07); Mari Ruiz, dos folios (AHPC, PN, 14-21(23), cuad. 7, f.15 r. 1488 . 06. 07); Diego Rodriguez, un folio PN, 14-21(23), cuad. 2, f 3 v 1488.06.07); Juan Gómez, un folio y medio (AHPC, 14-21(23), cuad. 2, f.4 v. 1488.06.07); Pedro de Baena, un folio y medio (AHPC, PN, 14-21(23) cuad. 2, f.7 v. 1488.06.07); Luis, dos folios (AHPC, PN, 14-21(23), cuad. 2, f.9 r. 1488.06.07).

${ }^{54} \mathrm{El}$ testamento de Gómez de Sandoval ocupa sólo la mitad del folio $10 \mathrm{r}$. del cuadernillo 4 del legajo 21 (AHPC, PN, 14-21(23), cuad. 4, f.10 r. 1488.07.08).

${ }^{55}$ AHPC, PN, 14-21(23), cuad. 4, f.10 r. 1488.07.08; AHPC, PN, 14-21(23), cuad. 4, f.10 v. 1488.07.08. Este día también otorgó su testamento Marina Ruiz, pero no conocemos la extensión del mismo, pues sólo se conserva la cabecera del documento (AHPC, PN, 14-21(23), cuad. 2, s.f. 1488.07.08).

${ }^{56}$ Ana Fernández, casi un folio (AHPC, PN, 14-21(23), cuad. 17, f.20 v. 1488.10.03); Inés González, un folio (AHPC PN, 14-21(23), cuad. 13, f.44 r. 1488.10.04); María Lechuga, un folio (AHPC PN, 14-21 (23) cuad. 12, f.21 r. 1488.10.24); Lope de Vitoria, un folio (AHPC,
PN, 14-21(23), cuad. 12, f.17 r. 1488.10.s.d).

${ }^{57}$ Isabel Alfonso, dos folios (AHPC, PN, 14-21(23), cuad. 13, f.33 r. 1488.10.01); Alfonso Fernández de Carreno, tres folios (AHPC, PN , 14-21(23), cuad. 17, f. $18 \mathrm{v}$. 1488.10.01); Alfonso Fernández, cuatro folios (AHPC PN, 14-21'(23), cuad. 13, f $38 \mathrm{v} .1488 .10 .02$ ) ; Fernando de Rodríguez, un folio y medio (AHPC, PN, 14-21(23), cuad. 12, f.10r. 1488.10.17); Inés Alfonso, dos folios (AHPC, PN, 14-21(23), cuad. 12 , f.13 v.1488.10.21); Pedro Fernández, un folio y medio (AHPC, PN, 14-21(23), cuad. 12, f.24 v. 1488.10.s.d).

${ }^{58}$ De todos los 69 testamentos otorgados en 1482 , sólo conocemos datos referidos a la extensión en 60 casos. De todos ellos, 20 ocupan menos de un folio y medio y 40 un folio y medio o más.
} 
datos referidos a su tamaño en 15 casos - el resto son testamentos conservados de forma fragmentaria - y todas tienen una extensión igual o superior a folio y medio. De ellas, 10 son especialmente largas, ocupando aproximadamente entre tres y cinco páginas ${ }^{59}$.

Sin duda, detrás de todos esos testamentos más escuetos de lo normal redactados durante el verano de 1488 , se adivina una presencia masiva de cordobeses enfermos y deseosos de otorgar sus últimas voluntades y, como consecuencia, un ritmo de trabajo frenético por parte de los escribanos y de los notarios de la ciudad. En ese sentido, algunos estudios sobre el tema hacen referencia a lo difícil que resultaba, en épocas de epidemias, contar con notarios suficientes para redactar actas testamentarias, hasta el punto de que, a veces, era necesario recurrir al testamento oral ${ }^{60}$. En otras ocasiones, el número de notarios aumentaba coincidiendo con la llegada de las epidemias. Es lo que sucedió en Toulouse durante la peste de 1348, a juzgar por los datos proporcionados por los libros de matrículas de notarios ${ }^{61}$. Otras veces, ante la presencia de un brote de peste, algunos escribanos se limitaban sólo a redactar actas testamentarias. Así, por ejemplo, en Lorca, con motivo de la epidemia de 1508, el concejo de esa ciudad otorgó licencia a un individuo llamado Juan Inglés para que se dedicase únicamente a un cometido: hacer testamentos $^{62}$.

Probablemente, las dificultades de los escribanos para ejecutar, en un corto período de tiempo, una gran cantidad de testamentos, que como es sabido solían ser documentos largos, les llevaron a optar por las llamadas «declaraciones testamentarias», que consistían en escuetas actas carentes de la formalidad de los testamentos y en las cuales apenas si se consignaban el lugar de enterramiento y los herederos y albaceas ${ }^{63}$. En este sentido, tal vez sea interesante destacar que, entre las actas notariales de Córdoba, hemos conseguido rescatar una fechada el 8 de junio de 1488, que parece ser una declaración testamentaria. En este documento se hace referencia a la visita que hicieron varios escribanos de la ciudad a las casas de Gil Martínez de Torquemada, situadas en la collación de Santa Marina, en las cuales se encontraba «echado en una cama, en un portal de las dichas casas», un hermano del dueño de la casa llamado Fernando, que declaraba encontrarse enfermo. A continuación, en el documento se recogían únicamente unas escuetas anotaciones referidas al lugar de sepultura, a las misas, al heredero

\footnotetext{
${ }^{59} \mathrm{El}$ más largo es el testamento de Marina Rodríguez, que tiene cinco folios y medio (AHPC, PN, 14-05(05), cuad. 4, f.8 r. 1478.01.15).

${ }^{60}$ José Luis BETRÁN, Ob. cit., p. 451.

${ }^{61}$ Richard Louis de LAVIGNE, La peste noire et la commune de Toulouse: le témoignane du livre des matricules des notaires, "Annales du Midi: Revue archéologique, historique et philologique de la France méridionale», 83, (Toulouse ,1971), p. 416 y tablas de las pp. 416 y
417 .

${ }^{62}$ Juan Francisco JIMÉNEZ ALCÁZAR, La peste de 1507-1508 en Murcia y Lorca: contagio y muerte, «Miscelánea Medieval Murciana», XVI (Murcia, 1990-1991), p. 135.

${ }^{63}$ Manuel José de LARA RÓDENAS, Epidemia, testamento e historia de las mentalidades. Morir de peste en la Huelva del siglo XVII, en Eliseo SERRANO MARTÍN (EDT.) Muerte, religiosidad y cultura popular. Siglos XIII-XVIII, Zaragoza, 1994, p. 400, nota no 14.
} 
y a los albaceas ${ }^{64}$. Tal vez la existencia de documentos de este tipo, coincidiendo con épocas de especial intensidad epidémica, obedezca a la imposibilidad de notarios y escribanos para ejecutar, en un solo día, un elevado número de testamentos. No en vano, el mismo día que se otorgó el documento citado, el 8 de junio, se registraron, en Córdoba, nueve testamentos ${ }^{65}$ y un codicilo ${ }^{66}$. A juzgar por la documentación conservada, este día y el anterior, el 7 de junio, en el que, como señalamos con anterioridad, se otorgaron 18 testamentos, fueron, de todo el año 1488, los dos días en los que se redactaron un mayor número de actas testamentarias. Le siguen en importancia, en relación al volumen de documentación testamentaria, los días $4^{67}$ y 11 de junio ${ }^{68}$, ya que en cada uno de ellos se registraron ocho testamentos.

Sin duda, todo ello refleja una actividad inusual a la que, desde luego, no debían de estar acostumbrados los notarios y escribanos de la ciudad, si tenemos en cuenta que, según se desprende de la documentación consultada, sólo se registra un volumen diario de testamentos superior a tres durante los meses de junio y julio de 1488. Sin embargo, en los restantes meses de ese año y a lo largo de 1482 y 1478, hemos podido comprobar que el número de testamentos por día nunca supera esa cantidad. Así, por ejemplo, en febrero y en abril de 1488, los dos únicos días que se otorgaron tres testamentos diarios fueron el 26 de febrero ${ }^{69}$ y el 11 de abril $^{70}$. Y durante todo el año 1482, la única jornada en la que se redactaron tres actas testamentarias fue el

${ }^{64} \mathrm{AHPC}, \mathrm{PN}, 14-21(23)$, cuad. 6, f.51 r. 1488.06.08.

${ }^{65}$ Los testadores son: Juana (AHPC, PN, 14-21(23), cuad. 7, f.21 v. 1488.06.08); María Fernández (AHPC, PN, 14-21(23), cuad. 7, f.22 v. 1488.06.08; Antonia Rodríguez (AHPC, PN, 14-21(23) cuad. 7, f.23 r. 1488.06.08); Catalina Fernández (AHPC, PN, 14-21(23), cuad. 2, f.10 r. 1488.06.08); Catalina Rodríguez (AHPC, PN, 14-21(23), cuad. 2, f.11 r. 1488.06.08); Isabel Fernández (ẢHPC, PN, 14-21(23), cuad. 2, f.11 v 1488.06.08); Juana (AHPC, PN, 14-21(23), cuad. 2 , f.12 v. 1488.06.08); Nicolás de Mesa (AHPC, 14-21'(23) cuad. 6, f.47 r. 1488.06.08); Catalina Rodríguez (AHPC, 14-21(23), cuad. 6, f.48 v. 1488.06.08).

${ }^{66}$ Se trata de un codicilo otorgado por Antón Rodríguez (AHPC, PN, 14-21(23), cuad. 7, f.21 r. 1488.06.08).

${ }^{67}$ Testamentos de Marina López (AHPC, PN, 14-21(23), cuad. 7, f.4 r. 1488.06.04); Catalina Rodríguez (AHPC, 14-21(23), cuad 7, f.4 v. 1488.06.04); testadora de nombre ilegible, apellidada Rodríguez (AHPC,'PN, 14-21(23), cuad. 7, f.5 r. 1488.06.04); Juan Rodriguez (AHPC, PN, 14-21(23) cuad.'7, f.6 r. 1488.06.04); Benito Rodríguez (AHPC PN, 14-21 (23), cuad. 7, f.6 v. 1488.06.04); Leonor Gómez (AHPC,PN, 14-21(23), cuad. 7 , f.7 y. 1488.06.04); Martín López, (AHPC, PN, 14-21(23), cuad. 7, f.8 r.'1488.06.04); Ruy García (AHPC, PN, 14-21(23), cuad. 7, f.8 v. 1488.06.04).

${ }^{68}$ Testamentos de Juan de Tales (AHPC, PN, 14-21(23), cuad, 6, f.54 r. 1488.06.11); Catalina

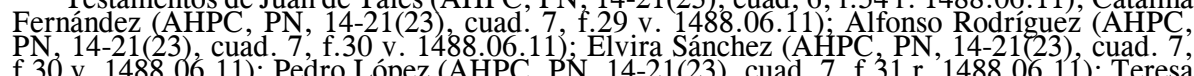
López (AHPC, PN, 14-21(23), cuad. 7, f.32 r. 1488.06.11); Juana Rodríguez (AHPC, PN, 1421(23), cuad. 7, f.32 v. 1488.06.11); Benita (AHPC, PN, 14-21(23), cuad. 2, f.18 v. 1488.06.11).

${ }^{69}$ Testamentos de Cristóbal Sánchez (AHPC, PN, 14-21(23), f.23 r. cuad. 3. 1488.02.26); Juan Pérez (AHPC, PN, 14-21(23), f.23 v. cuad. 3. 1488.02.26); Catalina Martínez (AHPC, PN, 14-21(23), f.24 v. cuad. 3. 1488.02.26).

${ }^{70}$ Testamentos de Gonzalo Ruiz (AHPC, PN, 14-21(23), cuad. 6, f.16 v. 1488.04 11); Antón Ruiz (AHPC, PN, 14-21(23), cuad. 6, f.17'v. 1488.04.11); Franscisco de Albornos (AHPC, PN, 14-21(23), cuad. 6 , f.18 r. 1488.04.11). 
29 de junio. ${ }^{71}$ Por su parte, en 1478 , el mayor volumen de testamentos - en este caso asciende a dos- corresponde únicamente a los días $4^{72}$ y 12 de abril $^{73}$.

\section{LA HUIDA DE LA PESTE}

Pero la lectura de los testamentos otorgados durante el verano de 1488 permite recabar también otros datos de tipo cualitativo referidos a esa epidemia. Por desgracia, tal y como es habitual entre la documentación testamentaria, no existen referencias explícitas a la peste ${ }^{74}$, pues, como es sabido, los escribanos se limitaban únicamente a consignar si los testadores se encontraban sanos o enfermos, pero sin hacer ninguna alusión al tipo de dolencia que les aquejaba. En ese sentido, analizando el estado de salud de los cordobeses que otorgaron su última voluntad en el año 1488, hemos podido comprobar que el $93.20 \%$ de ellos declaraban encontrarse enfermos ${ }^{75}$. Se trata, sin lugar a dudas, de un porcentaje muy elevado, que, en principio, puede ser indicativo de la sobremortalidad que se pudo desencadenar a consecuencia de la epidemia, aunque no conviene olvidar que dictar testamento en el transcurso de la enfermedad fue una tendencia habitual durante las centurias pasadas ${ }^{76}$. En el caso que nos ocupa, una prueba evidente de ello es que el número de cordobeses que otorgaron su última voluntad estando enfermos durante los años 1478 y 1482, en los que al parecer no se

\footnotetext{
${ }^{71}$ Testamentos de Pedro García de Higales (AHPC, PN, 18-01(02), f.11 v. 1482.06.29); Juan Garrote (AHPC, PN 18-01(02), f.17 v. 1482.06.29); Francisco de Ocaña (AHPC, PN, $18-01(02)$, f.18 v. 1482.06 .29$)$.

${ }^{72}$ Testamentos de Marina Fernández (AHPC, PN, 18-06(01), cuad. 11, s.f. 1478.04.04) y de Juana Rodríguez (AHPC, PN, 18-06(01), cuad. 11, s.f. 1478.04.04).

${ }^{73}$ Testamentos de Pedro de Aguayo (AHPC, PN, 14-12(14), cuad. 6, s.f. 1478.04.12) y de Teresa de Gama (AHPC, PN, 14-12(14), cuad. 7, s.f. 1478.04.12).

${ }^{74}$ En la Huelva del siglo XVII, M. J. de Lara pudo constatar que no era frecuente que se hiciese alusión a la peste en los testamentos, hasta el punto de que, durante la epidemia de 1602-1603, sólo el 10.23\% de los testadores hacía referencia a la enfermedad. Varias décadas después, durante la epidemia de 1649-1651, los testadores que aludían a la peste suponían el $31.37 \%$ ' (Manuel José de LARA RÓDENAS, Ob. cit., p. 402).

${ }^{75}$ Sobre el total de 345 testamentos otorgados a lo largo del año citado, se consigna el estado de salud de los otorgantes en 324 testamentos. En los 21 restantes desconocemos ese dato, bien porque el escribano no se detuvo en consignarlo o porque el deterioro de algunas actas notariales nos impide conocerlo. En cualquier caso, de esas 324 actas testamentarias en las que se especifica el estado de salud, 302 fueron otorgadas por testadores enfermos y 22 por testadores sanos.

${ }^{76}$ Así lo pudo constatar M.J. de Lara en el caso de la Huelva del siglo XVII (Manuel José de LARA RÓDENAS, Ob. cit., p. 408. Ver también el cuadro de esa página). También refiriéndose a esa ciudad, D. González Cruz señala que el porcentaje de testadores que declaraban encontrarse enfermos durante el difícil año de 1709 -que supuso el $94.8 \%$ - fue exactamente el mismo que se registró durante toda la primera mitad del siglo XVIII (David GONZÁLEZ CRUZ, Ob. cit., p. 514).
} 
detectó ningún fenómeno epidémico, también es muy elevado, pues supone, respectivamente, el $82.60 \%{ }^{77}$ el $81.96 \%$ del total $^{78}$.

En cualquier caso, la amenaza de la peste y de la muerte sí que se deja sentir de forma palpable en aquellos testamentos que fueron redactados por cordobeses que se habían alejado de la ciudad, lo cual permite imaginar ese deseo de huir del contagio al que ya se refirieron los médicos de la época. En el siglo XV, Alonso de Chirino recomendaba lo siguiente:

[...] Lo prinçipal es salir de aquella tierra onde se cabsa o está cabsada la pestilençia e lo más ante que pudiere $[\ldots]^{79}$.

También durante esa misma centuria, Velasco de Taranta señalaba:

[...] Prevención de la peste es huir no sólo del lugar, sino de toda la tierra comarcana, según dice Rhazes; y cuanto más lejos vaya, tanto más seguro estará $[\ldots]^{80}$.

A comienzos del siglo XVI, el doctor Fernando Alvarez afirmaba:

Dado que cuando en el aire hay corrupción que ocasiona pestilencia en los cuerpos humanos y en los alimentos, no todos pueden alejarse ni tienen medios para ello, es necesario ordenar la prevención y la cura; además, pocos de los que se apartan de los lugares infectados pueden huir tan rápido $\mathrm{y} \tan$ lejos que no lleven consigo o que no hallen donde van alguna infección, por la proximidad y por la comunicación de los que van y vienen continuamente $[\ldots]^{81}$

En el caso de Córdoba, fueron sobre todo los miembros de la oligarquía ciudadana los que tuvieron el privilegio de marcharse a sus fincas situadas en la sierra o a sus cortijos ubicados en la campiña, tratando de escapar de la peste y, en ocasiones, lo consiguieron. Así, por ejemplo, el 5 de junio de 1488, Rodrigo de Ravé otorgó su testamento en la sierra de Córdoba, en el pago del Carrascoso ${ }^{82}$. En ese documento se especificaba que el testador se encontraba sano y, probablemente, se libró de la enfermedad porque vivía cuatro meses más tarde ${ }^{83}$. En ese mismo lugar y ese mismo día también hizo testamento una sobrina suya, Bartolomina de Ravé. Esta última se declaraba

\footnotetext{
${ }^{77}$ Sobre el total de 26 testamentos resgistrados ese año, se consigna el estado de salud en 23 casos. De todos ellos, 19 testamentos fueron otorgados por personas enfermas y 4 por personas sanas.

${ }^{78}$ Sobre el total de 69 actas testamentarias otorgadas ese año, conocemos el estado de salud de los testadores en 61 testamentos, de los cuales, 50 fueron otorgadas por individuos enfermos y 11 por individuos sanos. 39.

${ }^{79}$ Alonso de CHIRINO, Menor daño de la medicina, ed. M ${ }^{\mathrm{a}}$ T. Herrera, Salamanca, 1973, p.

${ }^{80}$ Velasco de TARANTA, Tratado de la peste, en Tratados de la peste, ed. $\mathrm{M}^{\mathrm{a}} \mathrm{N}$. Sánchez, Madrid, 1993 , p. 33.

${ }^{81}$ Fernando AlVAREZ, Regimiento contra la peste, en Tratados de la peste, ed. cit., pp. $161-162$

${ }^{82}$ AHPC, PN, 14-21(23), cuad. 6, f.40 v. 1488.06.05.

${ }^{83}$ AHPC, PN, 14-21(23), cuad. 17, f.16 v. 1488.10.06.
} 
enferma, pero no tenemos más noticias de ella y, por tanto, ignoramos si consiguió sobrevivir ${ }^{84}$. A finales de ese mes, Rodrigo de Frías otorgó su testamento, estando enfermo, en el cortijo del Judío ${ }^{85}$. Unos días después, en el mes de julio, cuando testó su hermana Beatriz de Frías, él todavía vivía, pues aparece citado como heredero. Pero no volvemos a tener más noticias suyas $^{86}$. También durante el mes de julio, en el cortijo de la Cabeza de la Reina, dictó su última voluntad Fernando de Mesa, regidor del concejo de esa ciudad $^{87}$. Se encontraba en buen estado de salud y consiguió hacer frente al contagio o, tal vez, a la propia enfermedad, pues tenemos constancia documental de que vivía en $1494^{88}$.

En otras ocasiones, el buscar refugio fuera de las murallas de las ciudades no garantizaba la supervivencia. Así, por ejemplo, a finales de mayo de 1488, en una heredad de viñas situada en la sierra, ordenó su testamento Mencía de Lisón, esposa de Juan Muñiz ${ }^{89}$. La citada señora, que se encontraba enferma a la hora de otorgar ese documento, había muerto ya en septiembre de ese año ${ }^{90}$. A mediados de junio, Martín Alfonso de Montemayor consignaba la muerte de su esposa, Mencía de Mesa, que había tenido lugar el día anterior en la sierra de Córdoba ${ }^{91}$. Pocos días antes, otro vecino de la ciudad llamado Pedro de Baena, encontrándose enfermo, dictó su última voluntad en un lagar situado cerca de Córdoba, en el pago del Aguijón de Domingo Ruiz $^{92}$. Cuatro días más tarde, el día 11, otro documento certificaba su muerte, acaecida en ese lugar ${ }^{93}$. Ese mismo día, un acta notarial consignaba el fallecimiento, «en la syerra», de otro vecino de la ciudad llamado Antón ${ }^{94}$.

De ese deseo de escapar del contagio se hacen eco también, además de los testamentos, otros testimonios notariales. Así, por ejemplo, a mediados de noviembre de 1488, un documento se refería al pleito que existía entre Juan de Pedrosa y Juan García como consecuencia de que este último había salido de Córdoba «fuyendo de la pestilençia», pero dejando en la ciudad a dos

${ }^{84}$ AHPC, PN, 14-21(23), cuad. 6, f.40 r. 1488.06.05.

${ }^{85}$ AHPC, PN, 14-21(23), cuad. 8, f.1 r. 1488.06.28.

${ }^{86}$ AHPC, PN, 14-21(23), cuad. 8, f.18 v. 1488.07.s.d.

${ }^{87}$ AHPC, PN, 14-20(22), cuad. 5, f.23 r. 1488.07.30.

${ }^{88}$ AHPC, PN, 14-27(29), cuad. 4, f.21 v. 1494.02.24.

${ }^{89}$ AHPC, PN, 14-21(23), cuad. 6, f.43 v. 1488.05.31.

${ }^{90}$ AHPC, PN, 14-20(22), cuad. 9, f.39 r. 1488.09.24.

${ }^{91}$ AHPC, PN, 14-21(23), cuad. 2, f.25 r. 1488.06.16.

${ }^{92}$ AHPC, PN, 14-21(23), cuad. 2, f.7 v. 1488.06.07.

${ }^{93}$ Refiriéndose a la muerte de Pedro de Baena, en el citado documento puede leerse textualmente lo siguiente: «[...] fynó oy cerca desta çibdad en una heredad de casas bodega, lagar, pila, tynajas, que es çerca desta dicha çibdad, en el pago del Aguyjón [...]” (AHPC, PN', 14-21(23), cuad. 2, f.18 r. 1488.06.11).

${ }^{94} \mathrm{En}$ el documento se especificaba que este último, del que sólo conocemos su nombre de pila, había muerto unos siete días antes y que, antes de fallecer, había hecho testamento (AHPC, PN, 14-21(23), cuad. 2, f.19 v. 1488.06.11). 
esclavas que eran propiedad del primero y que habían muerto ${ }^{95}$. Poco después, a comienzos del mes de diciembre, otro testimonio se refería también al abandono de la ciudad por parte de un cirujano llamado maestro Pedro, que, durante los meses de verano, se había refugiado en un cortijo situado cerca de Espejo. Era una criada del cirujano citado la que declaraba que podía hacer seis meses que había estado en el cortijo de Sabariego, sirviendo a su amo, "que estaua foydo de la pestylençia ${ }^{96}$. Otras veces, son los contratos de arrendamiento de algunas fincas los que dejan entrever la obsesión de los hombres de la época por abandonar la ciudad en épocas de epidemias. En algunos de esos documentos se exigía que, en tales circunstancias, el arrendatario debía proporcionar cobijo al dueño de la finca y a su familia. Es lo que hemos podido comprobar en la carta de arrendamiento de unas casas lagar que eran propiedad del bachiller Francisco de Morales y que estaban situadas en la localidad cordobesa de la Rambla. En ese contrato, fechado en febrero de 1470, se establecía como condición:

[...] que sy en los dichos quatro años o en alguno o algunos dellos acaesçiere que, por causa de pestilençia o por otra causa alguna el dicho bachiller con su mujer e casa e fijos e compañía ouyere de yr e fuere a la dicha Rambla, que los dichos arrendadores o aquel o aquellos que en las dichas casas estouyeren e moraren e abytaren, los dexen e consyentan aposentar e estar en ellas $[\ldots]^{97}$.

Todos esos testimonios a los que acabamos de hacer alusión permiten adivinar la imagen un tanto desolada que debió de tener Córdoba a lo largo del verano de 1488, durante el cual, todos aquellos vecinos que poseían propiedades rurales debieron de salir apresuradamente hacia ellas. Probablemente, la vida municipal de la ciudad sufrió de manera especial los efectos de esa desbandada general puesta en práctica, en la inmensa mayoría de los casos, por quienes ocupaban sus principales puestos de gobierno, que eran, además, los que acumulaban en sus manos la inmensa mayoría de las explotaciones agrarias ${ }^{98}$. Es fácil suponer que, en plena epidemia, la prioridad de estos últimos no debió de ser otra que la de marcharse hacia sus posesiones rurales. En algunos lugares, la documentación conservada permite constatar el abandono de las ciudades, en épocas de peste, por parte de algunos miembros de los cabildos municipales. Es lo que sucedió, por ejemplo, en Santander, Bilbao y Barcelona con motivo de las epidemias que tuvieron lugar

\footnotetext{
${ }^{95}$ Según se desprende de la lectura del documento, Juan García se llevó consigo a varias esclavas, pero dejó a dos de ellas en poder de su padre y de su cuñada. Textualmente, en el acta notarial se consigna lo siguiente: " [...] el dicho Juan García se fué fuyendo de la pestilençia e lleuó las esclauas del rey nuestro señor e toda su gente de su casa e dexó aquí, en poder de su suegro e cuñada, a las dichas Penda e Ysabel e el dicho Juan García dise que se murieron [...]" (AHPC, PN, 14-21(23), cuad. 18, f.3 v. 1488.11.11).

${ }^{96}$ AHPC, PN, 14-21(23), cuad. 18, f.29 v. 1488.12.02.

${ }^{97}$ AHPC, PN, 14-06(06), cuad. 1, f.23 r. 1470.02.01.

${ }^{98}$ Ver, sobre este tema, Margarita CABRERA SÁNCHEZ, Nobleza, oligarquía y poder en Córdoba al final de la Edad Media, Córdoba, 1998, pp. 155 y ss.
} 
durante la época moderna.${ }^{99}$ En Córdoba, la falta de documentación municipal relativa al año $1488^{100}$ nos impide comprobar hasta qué punto el fenómeno epidémico que tuvo lugar durante ese año pudo provocar la deserción de una parte importante de los integrantes del cabildo municipal. Es posible que en 1488 sucediese algo similar a lo acontecido en la ciudad varias décadas después. En efecto, tenemos constancia de que durante las epidemias de 1522 y $1524 \mathrm{y}$, tras la huida de los regidores cordobeses, las sesiones del cabildo pasaron a celebrarse sólo una vez a la semana ${ }^{101}$. Además, durante el verano de ese último año, la epidemia de peste obligó a los oficiales del concejo a abandonar Córdoba y a celebrar las reuniones en la villa de Adamuz ${ }^{102}$.

Pero, ¿qué sucedía cuando ya era tarde para escapar? Muchos testimonios de la época nos hablan del rechazo que tuvieron que soportar los enfermos de peste por parte de sus propios familiares, quienes, en su empeño por escapar de la epidemia, no dudaron en abandonarlos. Así, por ejemplo, Giovanni Boccaccio, al aludir a la peste de 1348, señalaba:

[...] con tal espanto esta tribulación había entrado en el pecho de los hombres y de las mujeres, que un hermano abandonaba al otro y el tío al sobrino y la hermana al hermano y muchas veces la esposa al marido; y lo que es más grave y casi increíble, los padres y las madres evitaban visitar y cuidar a sus hijos, como si no fuesen suyos $[\ldots]^{103}$.

Unos siglos después, pero refiriéndose también a esa misma epidemia, Stephanus Baluzios, en su Vitae Paparum avenionensium afirmaba que el miedo a la peste era tal que, dentro de la propia familia, se llegaba a abandonar a quienes presentaban algunas manifestaciones físicas asociadas a la enfermedad:

[...] Tantus enim timor fere omnes invaserat quod statim, dum ulcus seu bossa, quod vel que ut in pluribus in inguine aut sub axella apparebat cuicumque, dimittebatur ab assistentibus, etiam quamtumcumque propinquis. Pater enim filium et filius patrem in grabato relinquebat $[\ldots]^{104}$.

Y el mismo temor al contagio transmite la crónica de Andrés Bernáldez, quien, refiriéndose a la pestilencia que azotó a Andalucía en 1507, afirmaba:

\footnotetext{
${ }^{99}$ Bartolomé BENNASSAR, Recherches sur les grandes épidémies dans le nord de l'Espagne à la fin du XVI siècle. Problèmes de documentation et de méthode, París, 2001, pp. 23-24; J. L. BETRÁN, Ob. cit., p. 250.

${ }^{100}$ Apenas si se han conservado, en el Archivo Municipal de la ciudad, actas capitulares anteriores a los años noventa del siglo $X V$. Con anterioridad a estos años, tan sólo existen algunas actas aisladas relativas al ano 1479.

${ }^{101}$ José Ignacio FORTEA PÉREZ, Córdoba en el siglo XVI: las bases demográficas y económicas de una expansión urbana, Córdoba, 1981, p. 217.

${ }^{102}$ Ibidem, p. 110.

${ }^{103}$ Giovanni BocCaccio, Decameron, ed. M. Hernández Esteban, Madrid, 2005, p. 121. p. 251 .

${ }^{104}$ Stephanus BALUZius, Vitae Paparum avenionensium, tomo 1, ed. G. Mollat, París, 1916,
} 
[...] y los vivos huían unos de otros, los que estaban en el campo de la villa, porque no se les pegase $[\ldots]^{105}$.

Por el contrario, en otras ocasiones, los testimonios ponen de manifiesto la solidaridad familiar puesta en práctica con algunos familiares enfermos, a los que, lejos de abandonar a su suerte, se les atendía convenientemente. En el caso de Córdoba, contamos con un precioso testimonio extraído de los protocolos notariales, fechado el 28 de junio de 1488 y otorgado por Sancho de Clavijo, jurado de la collación de San Salvador. En ese documento, este último declaraba, con cierta desesperación, que, por permanecer junto a varios miembros de su familia enfermos de peste, a los que tenía alojados en su propia casa y a los que proporcionaba los cuidados médicos necesarios, no podía ausentarse de la ciudad para atender a sus negocios. En ese registro notarial se consignaba textualmente lo siguiente:

En este dicho día, sábado veynte e ocho días del mes de junio del año del
nasçimiento del Ntro. Saluador Ihesu Xto de mill e quatroçientos e ochenta
e ocho años, pydió por testimonio el jurado Sancho de Clauyjo cómo tyene
en su casa enfermo a Pedro de Valdelomar, su sobryno, el qual vimos
enfermo con dos nasçidas en las dos yngles e asy mismo pidió por
testimonio cómo vimos enfermos de pestilençia a Ynés Gutiérres de
Valdelomar, su cuñada, hermana de su muger, a Ynés e a María, fijas de
Martín de Valdelomar e al dicho Martín de Valdelomar, todos ferydos de
pestylençia. E que por cabsa de les faser traer maestros e medesynas y
vysytándolos, por la qual cabsa dis que él non puede salir desta çibdad a
negoçiar cosa alguna ni entyende en cosa ninguna de su fasyenda ${ }^{106}$.

Pero, a pesar del estrecho contacto mantenido con esos familiares, todo conduce a pensar que Sancho de Clavijo se libró de la enfermedad o, en todo caso, si llegó a contraerla, es evidente que consiguió hacerle frente con éxito, pues nos consta que vivía en $1504^{107}$. También sobrevivió a la peste su cuñada Inés Gutiérrez de Valdelomar, la cual deja constancia documental de su existencia en 1494. ${ }^{108}$ No sabemos qué destino aguardaba al resto de los familiares del jurado que aparecen citados en ese documento, es decir, su cuñado, Martín de Valdelomar, y los tres hijos de este último: Pedro ${ }^{109}$ Inés y María. La documentación notarial no aporta datos referidos a los tres últimos con posterioridad al verano de $1488 \mathrm{y}$, por tanto, desconocemos si perecieron a causa de esa enfermedad. En relación a Martín de Valdelomar, en 1492, un individuo homónimo aparece otorgando un documento de venta de unas viñas situadas en la sierra de Córdoba, pero no sabemos con certeza

${ }^{105}$ Andrés Bernáldez, Crónica de los Reyes Católicos, vol. 70, ed. cit., p. 730.

${ }^{106}$ AHPC, PN, 14-21(23), cuad. 5, f.27 r. 1488.06.28.

${ }^{107}$ Archivo Municipal de Córdoba, Sección de Actas capitulares, Caj. 4, lib. 1, R. 7, Fot. 155. 1504.12.08.

${ }^{108}$ AHPC, PN, cuad. 11, 14-27(29), f.42 r. 1494.12.02.

${ }^{109}$ Sabemos que Pedro era hijo de Martín de Valdelomar gracias al codicilo de este último, otorgado el 26 de junio (AHPC, 14-21(23), cuad. 5 , f.23 r. 1488.06.26). 
si se trata del cuñado de Sancho de Clavijo ${ }^{110}$. En cualquier caso, lo que es evidente es que este último supo enfrentarse cara a cara con la enfermedad, llegando a poner en peligro su vida con el fin de intentar salvar a su familia. En conclusión, en ausencia de fuentes más idóneas, las utilización de los testimonios notariales permite analizar numerosos aspectos - hasta ahora desconocidos- de una de las muchas epidemias que asolaron la Andalucía de las postrimerías del Medievo.

Fecha de recepción del artículo: julio 2008.

Fecha de aceptación y versión final: enero 2009.

${ }^{110}$ AHPC, PN, 14-25(27), cuad. 5, f.32r, 1492.03.01. Por otra parte, tenemos constancia de que otro miembro de la familia de Sancho de Clavijo, su hija Leonor, murió también, a consecuencia de la peste, entre 1488 y 1494 . Sabemos que vivía en junio de 1488 (AHPC, PN, $14-20(22)$, cuad. 5, f.26 r. 1488.06.28) y que en 1494, cuando su padre otorgó testamento, después de aludir al fallecimiento de otro de sus hijos, que había tenido lugar hacia aproximadamente unos siete años, señalaba que «falleçió la dicha Leonor de pestylençia en esta çibdaḍ̣» (AHPC, PN, 18-05(06), f.1107 v. 1494.11.19). Tal vez Leonor fue otra víctima de la epidemia de 1488 . 


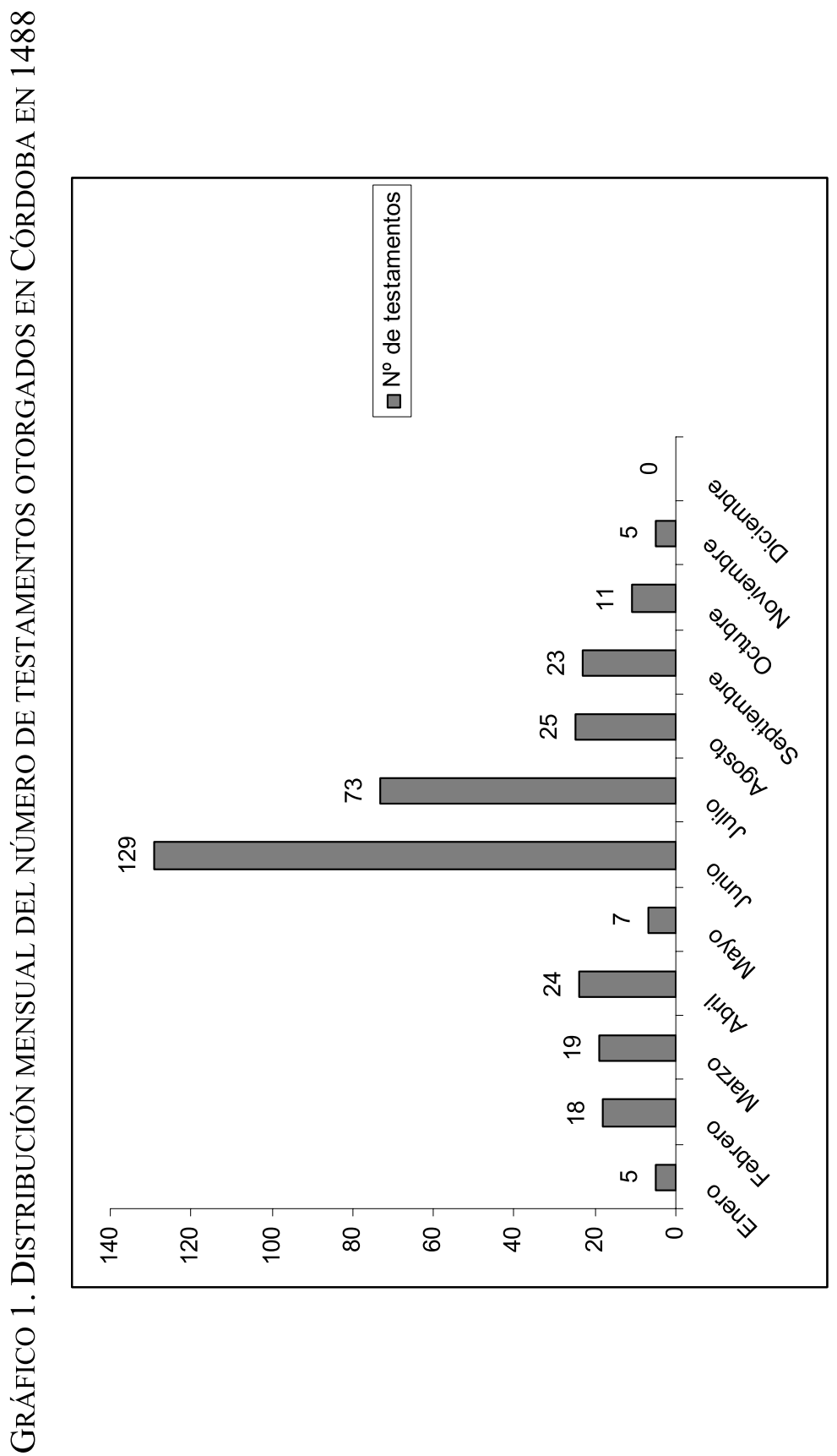

